\title{
An epidemiological survey on Cryptosporidium parvum infection of inhabitants in Chorwon-gun, Kangwon-do
}

\author{
Min $\mathrm{SEO}^{1)}$, Sun $\mathrm{HUH}^{2)}$, Jong-Yil $\mathrm{CHAI}^{3)}$ and Jae-Ran $\mathrm{YU}^{* 4)}$ \\ Department of Parasitology ${ }^{1)}$, College of Medicine, Dankook University, Chonan 330-714, \\ Department of Parasitology2), College of Medicine, Hallym University Chunchon 200-702, \\ Department of Parasitology 3), College of Medicine, Seoul National University, Seoul 110-790, \\ Department of Parasitology4), College of Medicine, Konkuk University, Chungju 380-701, Korea
}

\begin{abstract}
The present study was undertaken to know the infection status of Cryptosporidium parvum among the residents of Chorwon-gun, Kangwon-do in 1993. Total 461 fecal samples were collected from the inhabitants residing in Chorwon-gun during the period of August 12 to September 14, 1993. Fecal smears were prepared by formalin-ether sedimentation, and examined after modified acid fast staining. Of the 461 fecal samples, 9 (1.9\%) were positive for C. parvum oocysts. The positive cases were limited to thirties (4) patients, forties (3), and sixties (2), and no oocyst was detected in other age groups. The oocyst positive rate for male was $1.4 \%$ and that of female was $2.6 \%$.
\end{abstract}

Key words: Cryptosporidium parvum, infection status

The coccidian Cryptosporidium parvum is well known intestinal protozoa often causing severe life-threatening illness in immunocompromised individuals. Since the reported manifestation of $C$. parvum in laboratory mice by Chai et al. (1990), many studies on Cryptosporidium have been conducted in Korea. Rhee et al. (1991) reported the prevalence of Cryptosporidium spp. which ranged from $13.3 \%$ to $29.6 \%$ in various animals including mice, rats, pigs, dairy cattle, etc., and Wee et al. (1996) revealed $11.4 \%$ among 201 calves with diarrhea.

Livestocks, such as cattle, and drinking water are known to be important sources of infection. Human carriers without showing particular clinical symptoms have also important meaning in the epidemiological aspect. As a matter of fact, the epidemiological

- Received 12 April 2001, accepted after revision 21 May 2001.

*Corresponding author (e-mail: jaeran.yu@ mail.kku.ac.kr) survey conducted in 1996 by Chai et al on $C$. parvum infection among healthy residents of Seoul and Chollanam-do, and the oocyst positive rates were $0.5 \%$ in and $10.6 \%$, respectively. However, at the present, there are no available data with respect to $C$. parvum infection status from other areas in Korea. To clarify the infection status of Cryptosporidium in Korea, more efforts on epidemiological survey are necessary. The present study was undertaken to evaluate the infection status of C. parvum among the residents of Chorwongun, Kangwon-do. Data on the other parasite infection from stool examination of those residents have already been published in 1993 (Park et al., 1993).

Fecal samples (461 total) were collected from the inhabitants residing in Chorwon-gun during the period of August 12 to September 14 , 1993. Fecal smears were prepared by formalin-ether sedimentation, and examined after modified acid fast staining (Casemore et al., 1985). The smears were observed by light 
microscope for the presence of Cryptosporidium oocyst. The age of the studied population ranged from 2 to 89 , and the number of people in their fifties was the highest (119 persons). Of the sample examined, 271 were males and 190 were females.

Of the 461 fecal samples, 9 (1.9\%) were positive for Cryptosporidium oocysts. The positive cases were limited to the people in their thirties (4 patients), forties (3), and sixties (2), and no oocyst was detected in other age groups. The peak positive rate was recorded in the age group 30-39 (4.8\%), followed by $40-49(4.1 \%)$. The oocyst positive rate for male was $1.4 \%$, and that of female was 2.6\%. All positive inhabitants to $C$. parvum were negative to helminthic ova or other protozoan cyst.

Over the past decade, the role of Cryptosporidium as the agent of human diarrhea has been redefined from that of a rare opportunistic pathogen to a possible causative organism for mass infection by water-borne transmission route. Soave and Johnson (1988) reported prevalences of $0.6-20 \%$ in western countries and 4-20\% in developing countries. According to the report by CDC (1996), Cryptosporidium, along with Giardia spp., were responsible for $40 \%$ of US water borne outbreaks during the period 1993-1994, for which an etiological agent was found.

In Korea, however, such an outbreak has not been reported so far. This is probably due

Table 1. The prevalence of Cryptosporidium parvum infection by age of the inhabitants of Chorwon-gun, in 1993

\begin{tabular}{lcc}
\hline \hline Age group & $\begin{array}{c}\text { No. of exam. } \\
(\mathrm{M} / \mathrm{F})\end{array}$ & $\begin{array}{c}\text { No. of Positive } \\
(\%)\end{array}$ \\
\hline $0-9$ & $22(11 / 11)$ & $0(0.0)$ \\
$10-19$ & $31(19 / 12)$ & $0(0.0)$ \\
$20-29$ & $32(28 / 4)$ & $0(0.0)$ \\
$30-39$ & $84(51 / 33)$ & $4(4.8)$ \\
$40-49$ & $74(33 / 41)$ & $3(4.1)$ \\
$50-59$ & $119(62 / 57)$ & $0(0.0)$ \\
$60-69$ & $63(45 / 18)$ & $2(3.2)$ \\
$70<$ & $16(14 / 2)$ & $0(0.0)$ \\
unknown & $20(8 / 12)$ & $0(0.0)$ \\
Total & $461(271 / 190)$ & $9(1.9)$ \\
\hline
\end{tabular}

to difficulties in proper diagnosis of cryptosporidiosis, rather than the true absence of Cryptosporidium outbreak. Outbreaks of cryptosporidiosis in humans are often due to direct contact with infected animals, but many cases are associated with contacting contaminated water supplies (Pohjola et al., 1986). In fact, waterborne transmission of Cryptosporidium spp. is favored by many factors including a low infection dose, large number of infective oocyst shed by infected animal, resistance of oocyst to most environmental conditions and water treatment, and the small size of the oocyst (Smith, 1990).

All the nine positive patients with C. parvum in this study were over 30 years old. Logar et al. (1996) reported that the positive rate of $C$. parvum was higher in older age groups $(>14)$ than in younger age groups $(<14)$. Furthermore, according to the study of Chai et al. (1996), a peak positive rate was noted in the age groups 51-60 and 61-70, $13.2 \%$ and $15.9 \%$, respectively. It is not clear why the older age group is more susceptible to $C$. parvum than the younger people. One possible reason is that the active working population who are ready to Cryptosporidium infection in the rural area is mainly older age group. Since there are no effective drug therapies for Cryptosporidium, the prophylaxis is most important. For this purpose, the source of infection should be investigated more intensively and proper control measures against the sources should be established in the future. However, prior to these, the nationwide epidemiological survey is essential for the exact knowledge of infection status of C. parvum in our country. From the present study, it was revealed that C. parvum was infected in $1.9 \%$ of the inhabitants of Chorwon-gun, Kangwon-do.

\section{REFERENCES}

Casemore DP, Annstrong M, Sands RL (1985) Laboratory diagnosis of Cryptosporidiosis. $J$ Clin Pathol 38: 1337-1341.

CDC (1996) Surveillance for Waterborne-DiseaseOutbreaks-United States, 1993-1994. Morbidity and Mortality Weekly Report 45: 1- 
33.

Chai JY, Shin SM, Yun CK, et al. (1990) Experimental activation of cryptosporidiosis in mice by immunosuppression. Korean $J$ Parasitol 28: 31-37.

Chai JY, Lee SH, Guk SM, Lee SH (1996) An epidemiological survey of Cryptosporidium parvum infection in randomly selected inhabitants of Seoul and Chollanam-do. Korean J Parasitol 34: 113-119.

Logar J, Poljsak-Prijatelj M, Andolvic A (1996) Incidence of Cryptosporidium parvum in patients with diarrhea. $J$ Eukaryot Microbiol 43: $67 \mathrm{~S}$.

Park MS, Kim SW, Yang YS, et al. (1993) Intestinal parasite infection in the inhabitants along the Hantan River, Chorwon-gun. Korean J Parasitol 31: 375378.
Pohjola S, Jokipii AMM, Jokipii L (1986) Sporadic cryptosporidiosis in a rural population is asymptomatic and associated with contact to cattle. Acta Vet Scand 27: 91-102.

Rhee JK, Seu YS, Park BK (1991) Isolation and identification of Cryptosporidium from various animals in Korea. I. Prevalence of Cryptosporidium in various animals. Korean $J$ Parasitol 29: 139-148.

Smith HV, Rose JB (1990) Waterbonre cryptosporidiosis. Parasitol Today 6: 8-12.

Soave R, Johnson WD (1988) Cryptosporidium and Isospora belli infection. J Infect Dis 157: 225-229.

Wee SH, Joo HD, Kang YB (1996) Evaluation for detection of Cryptosporidium oocysts in diarrheal feces of calves. Korean $J$ Parasitol 34: 121-126. 